\title{
Analisis Promosi Terhadap Keputusan Pembelian Jasa Wedding Organizer Ahsya Management Di Bandar Lampung
}

\author{
Raditte Husin $^{1 *}$, Maria Elina ${ }^{1}$, Tiara Puspa Maharani ${ }^{2}$ \\ ${ }^{1}$ Universitas Sang Bumi Ruwa Jurai \\ *Correspondence: raditte.husin@fe.saburai.ac.id
}

\begin{abstract}
Abstrak.
Tujuan penelitian ini untuk mengetahui pengaruh promosi terhadap keputusan pembelian jasa wedding organizer ahsya management di Bandar Lampung. Metode penelitian yang digunakan dalam penelitian ini menggunakan metode penelitian kuantitatif deskriptif. Metode pengumpulan data yang digunakan berupa data primer dan data sekunder. Teknik pengumpulan data yang digunakan adalah observasi dan quisioner. Sampel yang digunakan dalam penelitian ini berjumlah 53 customer wedding organizer Ahsya Management. Hasil pengujian hipotesis mengenai pengaruh promosi terhadap keputusan pembelian jasa wedding organizer Ahsya Management diperoleh melalui perhitungan uji-t. Hasil penelitian didapat variabeal promosi memiliki kontribusi dan berpengaruh signifikan terhadap keputusan pembelian jasa wedding organizer Ahsya Management. Pengaruh nyata promosi terhadap keputusan pembelian dapat ditunjukkan dengan nilai $\mathrm{R}$ square $=0,894$ atau sebesar $89,4 \%$ sedangkan sisanya sebesar $10,6 \%$ dipengaruhi oleh faktor lain yang tidak diteliti dalam penelitian ini.
\end{abstract}

Kata kunci : Ahsya Management, Keputusan Pembelian, Promosi, Wedding Organizer

\begin{abstract}
.
The purpose of this study was to determine the effect of promotion on purchasing decisions for Ahsya's wedding organizer management services in Bandar Lampung. The research method used in this research is descriptive quantitative research method. Data collection methods used in the form of primary data and secondary data. Data collection techniques used are observation and questionnaires. The sample used in this study amounted to 53 customer wedding organizer Ahsya Management. The results of testing the hypothesis regarding the effect of promotion on purchasing decisions for Ahsya Management's wedding organizer services were obtained through t-test calculations. The results showed that the promotion variable had a significant contribution and influence on purchasing decisions for Ahsya Management's wedding organizer services. The real effect of promotion on purchasing decisions can be shown by the value of $R$ square = 0.894 or $89.4 \%$ while the remaining $10.6 \%$ is influenced by other factors not examined in this study.
\end{abstract}

Keywords: Ahsya Management, Purchase Decision, Promotion, Wedding Organizer

\section{PENDAHULUAN}

Perkembangan dunia usaha saat ini tidak lepas dari adanya persaingan bisnis antar perusahaan. Persaingan untuk memperebutkan calon pelanggan dan mempertahankan pelanggan yang sudah ada merupakan tantangan yang semakin besar dan harus dihadapi oleh perusahaan dalam memasarkan produknya (Heryanto, 2015). Untuk dapat mempertahankan kredibilitas perusahaan dari munculnya perusahaanperusahaan baru yang saling bersaing dalam mendapat minat dan memperoleh keuntungan usaha dari masyarakat luas. Perusahaan haruslah menonjolkan produknya dari persaingan dengan kebijaksanaan harga, produk, distribusi dan promosi (Lontoh, 2016). Perusahaanperusahaan yang telah lama berdiri berupaya untuk memperkenalkan usahanya dan bidang-bidang bisnis apa saja yang mereka miliki kepada masyarakat. Oleh karena itu, hal-hal yang berpotensi untuk mempengaruhi keputusan pembelian konsumen harus lebih diperhatikan (Permana, 2017). 
Perusahaan harus bekerja keras membuat kebijakan-kebijakan strategis baru dalam menjual produk dan jasa mereka dalam kaitannya menghadapi persaingan yang ketat dengan competitor yang dapat memberikan value yang lebih besar kepada customer (Aziz, 2019). Perusahaan harus bisa menentukan strategi pemasaran yang tepat agar usahanya dapat bertahan dan tujuan utama dari perusahaan tersebut dapat tercapai. Konsumen akan membuat perbandingan antara yang mereka berikan dengan apa yang mereka dapat (Adi et al., 2018).

Ada beberapa faktor yang menjadi alasan suatu perusahaan bisa mendapat tempat tersendiri di hati masyarakat, di antaranya adalah bagaimana sebuah perusahaan memberikan tingkat harga yang kompetitif (Atmoko, 2018), membentuk citra dan membangun reputasinya di masyarakat dengan baik (Jenty \& Setyanto, 2019) serta kualitas produk yang ditawarkan kepada konsumen adalah kualitas terbaik (Fadhli \& Pratiwi, 2021). Perlu kita ketahui juga bahwa, untuk menarik minat konsumen membeli produk yang ditawarkan maka dibutuhkan adanya juga promosi yang efektif. Menariknya promosi yang ditawarkan akan mempengaruhi minat konsumen untuk mencoba mengkonsumsi produk tersebut (Agustin, 2016).

Promosi adalah upaya untuk memberitahukan atau menawarkan produk atau jasa pada dengan tujuan menarik calon konsumen untuk membeli atau mengkonsumsinya (Ariyanto et al., 2020). Kegiatan promosi erat hubungannya dengan usaha dari suatu perusahaan dalam rangka memasarakan produk yang dihasilkan dengan harapan agar dapat dicapai tingkat volume penjualan tertentu dan dapat memberikan keuntungan yang diharapkan (Nuzleha et al., 2019). Iklan yang baik akan menyampaikan pesan dan informasi detail dan selengkap mungkin sehingga iklan yang ditampilkan menjadi sangat menarik dan mendapatkan kepercayaan dari konsumen untuk melakukan keputusan pembelian (Setyarko, 2016).

Wedding organizer adalah salah satu usaha yang cukup menjanjikan dan memiliki peluang untuk dikembangkan (Kamisi et al., 2017) di masa seperti sekarang dimana pola dan gaya hidup masyarakat yang serba instan dan cepat (Fitriana \& Darmawan, 2021) dalam persiapan pernikahan mendapat bantuan dari sebuah wedding organizer untuk menangani segala kebutuhan dalam rangka penyelenggaraan perhelatan pernikahan (Pinaraswati, 2021). Ahsya Management adalah salah satu perusahaan di Bandar Lampung yang bergerak di bidang jasa yang menangani wedding organizer, wedding singer dan Nasyid. Ahsya Management merupakan usaha wedding organizer yang berfokus pada acara pernikahan.

Dari data yang didapat melalui wawancara langsung, jumlah event yang ditangani ahsya Management dari bulan januari sampai bulan desember 2019 sejumlah 78 event yang jauh lebih banyak jika dibandingkan dengan tahun 2020 dari bulan januari sampai bulan desember yang hanya menangani 53 event saja.

Ahsya Management menentukan besarnya dana (price list) dengan varian harga tertentu yang harus dikeluarkan oleh konsumen disesuaikan dengan jumlah tamu yang akan diundang. Harga yang ditetapkan untuk paket akad di rumah berkisar 7 juta rupiah harga tersebut sudah meliputi, dekorasi akad di dalam rumah, makeup pengantin, pakaian pengantin, photographer dan videographer, serta sejumlah kru yang akan membantu pelaksanaan acara. Selain itu juga paket untuk di hotel sekitar 50 juta rupiah sampai 76 juta rupiah. Konsumen akan mendapat fasilitas jadwal meeting minimal dua kali guna membahas konsep serta susunan acara yang akan diselenggarakan. 
Penelitian sejenis telah banyak diteliti oleh peneliti lain antara lain Penelitian oleh Haryoko, dkk mengenai Pengaruh Harga dan Kualitas Pelayanan Terhadap Kepuasan Konsumen (Haryoko et al., 2020). Penelitian oleh Efnita (20217) tentang Pengaruh variasi produk, kualitas pelayanan, harga dan lokasi terhadap kepuasan konsumen (Efnita, 2017). Penelitian oleh Ali (2020) mengenai Pengaruh Promosi Melalui Media Sosial dan Word Of Mouth Terhadap Keputusan Konsumen (Ali, 2020). Dan yang terakhir, penelitian oleh Budiman \& Asj'ari (2021) mengenai Pengaruh Marketing Mix Terhadap Keputusan Calon Pengantin Menggunakan Jasa Wedding Organizer (Budiman \& Asj'ari, 2021).

Berdasarkan uraian dan penelitian sebelumnya yang sudah dijelaskan di atas. Penelitian ini bertujuan untuk meneliti lebih lanjut mengenai pengaruh Promosi Terhadap Keputusan Pembelian Jasa Wedding Organizer Ahsya Management di Bandar Lampung.

\section{METODE PENELITIAN}

Metode penelitian ini adalah kuantitatif deskriptif. Lokasi penelitian ini dilakukan di Ahsya Management yang terletak di Gg. Bumi Teliyu 2 Blok B33, Labuhan Ratu, Bandar Lampung. Waktu penelitian ini dilakukan mulai dari bulan Maret 2021 Juni 2021. Variable penelitian ini adalah Promosi (X) dan Keputusan Pembelian (Y). Teknik pengumpulan data dalam penelitian ini dengan menggunakan observasi, questioner, dan wawancara.
Populasi dalam penelitian ini adalah seluruh konsumen Ahsya Management tahun 2020 sebanyak 53 orang. Karena populasi kurang dari 100 maka seluruh populasi dijadikan sampel. metode yang digunakan untuk membuktikan kebenaran data-data yang akan di analisis dengan cara menguji data menggunakan program SPSS. Analisis data pada penelitian ini menggunakan uji t untuk menguji hipotesis apakah promosi (X) berpengaruh terhadap keputusan pembelian (Y) dengan hipotesisnya sebagai berikut:

$\mathrm{H}_{0}$ : tidak ada pengaruh antara promosi (X) terhadap keputusan pembelian (Y).

Ha : terdapat pengaruh antara promosi (X) terhadap keputusan pembelian (Y).

Pengambilan keputusan dilakukan dengan melihat nilai signifikansi pada tabel Coefficients. Dasar pengujian hasil regresi dilakukan dengan tingkat kepercayaan sebesar $95 \%$ atau dengan taraf signifikannya sebesar 5\% $(\alpha=0,05)$. Adapun kriteria dari uji statistik t:

Jika nilai signifikansi uji $\mathrm{t}>0,05$ maka $\mathrm{H}_{0}$ diterima dan Ha ditolak. Artinya tidak ada pengaruh antara promosi $(\mathrm{X})$ terhadap keputusan pembelian (Y).

Jika nilai signifikansi uji $\mathrm{t}<0,05$ maka $\mathrm{H}_{0}$ ditolak dan $\mathrm{Ha}$ diterima. Artinya terdapat pengaruh antara promosi (X) terhadap keputusan pembelian (Y).

\section{HASIL DAN PEMBAHASAN}

Dari data yang didapat lalu dianalisis menggunakan uji-t sehingga mendapatkan hasil sebagai berikut.

Tabel 1. Hasil Analisis Regresi Linear Sederhana

\begin{tabular}{|c|c|c|c|c|c|c|}
\hline & \multirow{2}{*}{ Model } & \multicolumn{2}{|c|}{$\begin{array}{c}\text { Unstandardized } \\
\text { Coefficients }\end{array}$} & $\begin{array}{c}\text { Standardized } \\
\text { Coefficients }\end{array}$ & \multirow{2}{*}{$\mathrm{t}$} & \multirow{2}{*}{ Sig. } \\
\hline & & B & $\begin{array}{l}\text { Std. } \\
\text { Error }\end{array}$ & Beta & & \\
\hline \multirow[t]{2}{*}{1} & (Constant) & 1.688 & 1.403 & \multirow[b]{2}{*}{.946} & 1.203 & .235 \\
\hline & Promosi & 1.103 & .053 & & 20.757 & .000 \\
\hline
\end{tabular}


Dari hasil perhitungan tabel 1 maka dapat dibentuk persamaan yaitu : $\mathrm{Y}=1,688$ $+1,103 X$. Angka koefisien regresi sebesar 1,688. Jika terjadi penambahan promosi sebesar $1 \%$ maka keputusan pembelian akan meningkat sebesar $1,103 \%$. Diketahui pula nilai $t_{\text {hitung }}$ sebesar 20,757 maka dapat dibandingkan dengan $t_{\text {tabel }}$ yaitu sebesar 1,674. Karena nilai $t_{\text {hitung }}>t_{\text {tabel }}$ serta nilai
Sig. dibawah 5\% atau Alpha $<0,00$ maka dapat disimpulkan bahwa ada pengaruh positif dan signifikan Promosi (X) terhadap Keputusan Pembelian (Y).

Selanjutnya dilakukan uji determinasi $\left(\mathrm{R}^{2}\right)$ untuk untuk mengetahui besarnya pengaruh Promosi (X) terhadap Keputusan Pembelian (Y) dalam analisis regresi sederhana. Berikut hasilnya:

Tabel 2. Hasil Uji Koefisien Determinasi

\begin{tabular}{|c|c|c|c|c|}
\hline Model & $\mathrm{R}$ & R Square & $\begin{array}{l}\text { Adjusted R } \\
\text { Square }\end{array}$ & $\begin{array}{c}\text { Std. Error of the } \\
\text { Estimate }\end{array}$ \\
\hline 1 &, $946^{\mathrm{a}}$ & .894 & .892 & 1.053 \\
\hline
\end{tabular}

Berdasarkan table 2 didapat, Nilai $\mathrm{r}$ Square sebesar 0,894 dengan demikian mampu menjelaskan bahwa promosi berkontribusi terhadap keputusan pembelian yaitu sebesar $89,4 \%$ sedangkan $10,6 \%$ dipengaruhi oleh faktor-faktor lain yang tidak diteliti dalam penelitian ini. Std. Error of the Estimate adalah sebesar 1,053 hal ini menunjukan bahwa semakin kecil Std. Error of the Estimate maka model semakin baik.

\section{KESIMPULAN}

Berdasarkan hasil penelitian dapat disimpulkan bahwa Dari hasil perhitungan analisis regresi sederhana didapatkan bentuk persamaan $\mathbf{Y}=\mathbf{1 , 6 8 8}$ + 1,103X. Angka koefisien regresi sebesar 1,688. Jika terjadi penambahan promosi sebesar 1\% maka keputusan pembelian akan meningkat sebesar $1,103 \%$. Nilai r Square sebesar 0,894 dengan demikian mampu menjelaskan bahwa promosi berkontribusi terhadap keputusan pembelian yaitu sebesar $89,4 \%$ sedangkan $10,6 \%$ dipengaruhi oleh faktor-faktor lain yang tidak diteliti dalam penelitian ini.

Berdasarkan hasil penelitian ini saya menyarankan kepada Ashya Management untuk lebih memperhatikan keramahan dalam melayani konsumen karna dapat mempengaruhi keputusan konsumen. Wedding Organizer Ahsya Management sebaiknya mengevaluasi promosi yang ditawarkan karena konsumen masih ada yang ragu-ragu dalam mengambil keputusan pembelian.

\section{DAFTAR PUSTAKA}

Adi, D. O. R. K., Fathoni, A., \& Hasiolan, L. B. (2018). Pengaruh Kualitas Pelayanan, Harga Dan Promosi Terhadap Keputusan Pembelian Produk Cke Teknik Semarang. Journal of Management, 4(4), 1-22.

Agustin, M. Y. (2016). Analisis Kualitas Produk, Harga Dan Promosi Terhadap Keputusan Pembelian Motor Honda Vario (Studi Kasus Pada Tridjaya Motor Dealer Resmi Motor Honda Cabang Girian - Bitung). Jurnal Berkala Ilmiah Efisiensi, 16(3), 472483.

Ali, K. (2020). Pengaruh Promosi Melalui Media Sosial Dan Word Of Mouth Terhadap Keputusan Konsumen Memilih Wedding Organizer (Studi Pada Konsumen Art Project Lampung di Kecamatan Trimurjo Lampung Pengaruh Promosi Melalui Media Sosial Dan Word Of Mouth Terhadap Keputusan. Jurnal Manajemen Dan Bisnis (JMB), 1(2), 11-24.

Ariyanto, A., Nuryani, A., \& Sunarsi, D. (2020). Pengaruh Store Atmosphere 
Dan Promosi Terhadap Keputusan Pembelian Pada Alfamart BSD Tangerang Selatan. Jurnal Ekonomi Efektif, 3(1), 29-36. https://doi.org/10.32493/jee.v3i1.7272

Atmoko, T. P. H. (2018). Strategi Pemasaran Untuk Meningkatkan Volume Penjualan Di Cavinton Hotel Yogyakarta. Journal of Indonesian Tourism, Hospitality and Recreation, 1(2), 83-96. https://doi.org/10.17509/jithor.v1i2.137 69

Aziz, N. (2019). Analisis Pengaruh Kualitas Produk, Harga, Promosi Terhadap Keputusan Pembelian Air Minum Dalam Kemasan (AMDK) Merek Aicos Produksi PT. Bumi Sarimas Indonesia. 1-9. https://doi.org/10.31219/osf.io/w6dt5

Budiman, A., \& Asj'ari, F. (2021). Pengaruh Marketing Mix Terhadap Keputusan Calon Pengantin Menggunakan Jasa Wedding Organizer Pada Pameran Wedding Royal Plaza Surabaya (2019). Journal of Sustainability Bussiness ..., 2(3), 1-15. http://jurnal.unipasby.ac.id/index.php/j sbr/article/view/4271\%0Ahttp://jurnal. unipasby.ac.id/index.php/jsbr/article/do wnload/4271/3152

Efnita, T. (2017). Effect of Variation of Products, the Service Quality, Price and Location on Customer Satisfaction Wedding Organizer. Jurnal AdBispreneur, 2(2), 107-115.

Fadhli, K., \& Pratiwi, N. D. (2021). Pengaruh Digital Marketing, Kualitas Produk, dan Emosional terhadap Kepuasan Konsumen Poskopi ZIO Jombang. Jurnal Inovasi Penelitian, 2(2), 603-612. https://stp-mataram.ejournal.id/JIP/article/view/684

Fitriana, R., \& Darmawan, D. R. (2021). Workout sebagai gaya hidup sehat wanita modern. Satwika: Kajian Ilmu Budaya Dan Perubahan Sosial, 5(2), 199-213.

https://doi.org/10.22219/satwika.v5i2.1
7571

Haryoko, U. B., Delimah Pasaribu, V. L., \& Ardiyansyah, A. (2020). Pengaruh Harga Dan Kualitas Pelayanan Terhadap Kepuasan Konsumen Pada Firman Dekorasi (Wedding Organizer). Point, 2(1), 1-17. https://doi.org/10.46918/point.v2i1.566 Heryanto, I. (2015). Analisis Pengaruh Produk, Harga, Distribusi, dan Promosi Terhadap Keputusan Pembelian serta Implikasinya pada Kepuasan Pelanggan. Jurnal Ekonomi, Bisnis \& Entrepreneurship, 9(2), 80-101. https://doi.org/2443-2121Heryanto, I. (2015). Analisis pengaruh produk, harga, distribusi, dan promosi terhadap keputusan pembelian serta implikasinya pada kepuasan pelanggan. Ekonomi, Bisnis \& Entrepreneurship, 9(2), 80-101. http://doi.org/2443-2121

Jenty, F., \& Setyanto, Y. (2019). Pemanfaatan Event sebagai Upaya Public Relations dalam Membangun Reputasi Perusahaan (Studi pada PT. XYZ sebagai pendukung kegiatan Asian Games 2018). Prologia, 2(2), 320-326.

https://doi.org/10.24912/pr.v2i2.3593

Kamisi, H. La, Lekahena, V. N. J., \& Hiariey, S. L. (2017). Analisis kelayakan usaha pengolahan ikan asap di Kelurahan Faudu, Kecamatan Pulau Hiri, Kota Ternate. Agrikan: Jurnal Agribisnis Perikanan, 10(1), 34-37. https://doi.org/10.29239/j.agrikan.10.1. 34-37

Lontoh, M. N. (2016). Analisis Pengaruh Bauran Promosi Terhadap Keputusan Pembelian Mobil Toyota Pada Pt. Hasjrat Abadi Manado Cabang Tendean. Jurnal Berkala Ilmiah Efisiensi, 16(01), 515-525.

Nuzleha, Yamin, Y., \& Novalia. (2019). ENGARUH PROMOSI TERHADAP EFEKTIVITAS KERJA KARYAWAN PADA PT. KARYA NIAGA DI BANDAR LAMPUNG. Ekombis Sains: Jurnal Ekonomi, 
Keuangan Dan Bisnis, 4(1), 17-26.

Permana, D. I. (2017). PENGARUH PROMOSI

KEPUTUSAN

TERHADAP PEMBELIAN

PRODUK LANTAI KAYU DAN

PINTU PT.PIJI DI JAWA TIMUR. PERFORMA: Jurnal Manajemen Dan Start-Up Bisnis, 2(1), 116-123. https://doi.org/10.35797/jab.0.0.2017.1 8378.

Pinaraswati, S. O. (2021). Analisis Pengaruh Harga, Promosi, Reputasi, dan Kualitas Pelayanan Terhadap Keputusan Pengguna Jasa Wedding and Event Organizer di Surabaya. GEMA EKONOMI (Jurnal Fakultas Ekonomi), 10(2), 125-143.

Setyarko, Y. (2016). Analisis Persepsi Harga, Promosi, Kualitas Pelayanan, dan Kemudahan Penggunaan Terhadap Keputusan Pembelian Produk Secara Online. Ekonomika Dan Manajemen, 5(2), 128-147. 